\title{
Metodologia para avaliação do efeito sistêmico e local da LLLT na osseointegração de implantes dentários em mandíbula de coelhos: nota prévia
}

\section{Methodology protocol for assess systemic and local effects of LLLT on osseointegration of dental implants in the rabbits jaws}

Luciano Mayer Marília Gerhardt de Oliveira** Fabrício P. Massotti ${ }^{* * *}$ Fernando V. Gomes ${ }^{* * *}$

Viviane Guyoti*** Félix H. D. González ${ }^{* * * *}$ João B. B. Weber

\section{Resumo}

Objetivos: descrever a técnica cirúrgica e a sequência laboratorial utilizada na obtenção de dados por meio de dosagem hormonal, análise da frequência de ressonância (AFR), tomografia computadorizada de feixe cônico (TCFC), microscopia eletrônica de varredura $(M E V)$, espectrometria por dispersão de energia (EDS) e análise histológica e histomorfométrica da região perimplantar pós-terapia com laser não ablativo (LLLT) em modelo experimental coelho. Materiais e método: foram utilizados 40 coelhos machos, raça Nova Zelândia, distribuídos em cinco grupos, sendo dois grupos designados controle (Cl e CII) e três grupos designados experimentais (EI, EII, EIII). Os cinco grupos foram submetidos a coletas sanguíneas para dosagens de tri-iodotironina $\left(T_{3}\right)$, tiroxina $\left(T_{4}\right)$, cálcio e albumina, sendo o grupo $\mathrm{Cl}$ considerado controle hematológico absoluto. Nos demais grupos (CII, El, Ell e EIII), foram realizadas a extração do incisivo inferior esquerdo e a colocação de um implante imediato com aferição da frequência de ressonância (AFR). Nos grupos experimentais, foi realizada laserterapia com três doses distintas $\left(E I=70 \mathrm{~J} / \mathrm{cm}^{2}\right.$, $E I I=35 \mathrm{~J} / \mathrm{cm}^{2}, E I I I=140 \mathrm{~J} / \mathrm{cm}^{2}$. Aos 45 dias, os animais dos grupos CII, El, Ell e EIII foram novamente submetidos à aferição da frequência de ressonância, foram mortos e tiveram suas mandíbulas dissecadas e avaliadas por TCFC, MEV e EDS. As mandíbulas foram incluídas, seccionadas e coradas com coloração de HE, picrosirius-red e azul de toluidina para análise histomorfométrica da extensão linear de contato entre osso e implante (ELCOI) e a área óssea (AO) por meio de microscopia ótica. Considerações finais: apresenta-se um roteiro que pode servir de modelo para colegas pesquisadores.

Palavras-chave: Implantes dentários. Terapia a laser de baixa intensidade. Metodologia. Coelhos.

Doutor em CTBMF. Departamento de Cirurgia e Traumatologia Bucomaxilofaciais da Faculdade de Odontologia da Pontifícia Universidade Católica do Rio Grande do Sul (PUCRS), RS, Brasil.

Pesquisadora por Produtividade CNPq, preceptora do Serviço de CTBMF do Hospital Cristo Redentor - Grupo Hospitalar Conceição (GHC), RS, Brasil. Mestre em Clínica Odontológica/CTBMF. Departamento de Cirurgia e Ortopedia da Faculdade de Odontologia da Universidade Federal do Rio Grande do Sul (UFRGS), RS, Brasil.

**** Mestre em Ciências Veterinárias. Laboratório de Análises Clínicas Veterinárias (LACVet) da UFRGS, RS, Brasil.

B**** Bolsista de Produtividade em Pesquisa do CNPq. Professor de Bioquímica Clínica e professor orientador do Programa de Pós-Graduação em Ciências Veterinárias. Faculdade de Veterinária da UFRGS, RS, Brasil.

****** Professor coordenador do Departamento de Odontologia Preventiva da Faculdade de Odontologia da PUCRS, RS, Brasil. 


\section{Introdução}

A evolução exponencial da Implantodontia nos últimos anos denota a sua importância no desenvolvimento da estética e da função do complexo odontológico maxilomandibular, tendo em vista o alto nível de exigência requerido pelos pacientes quando da necessidade de reposição de dentes perdidos. Simultaneamente, pesquisadores têm estudado meios para a obtenção de prognósticos clínicos e cirúrgicos mais previsíveis e favoráveis. Numa avaliação histórica, desde a década de 1960, quando se deu início à osseointegração - um método de reabilitação por implantes de titânio idealizado pelo médico sueco Per-Ingvar Branemark -, tem-se observado mudanças no desenho, no tamanho e no tratamento da superfície desses implantes dentários, com a finalidade de acelerar o processo de osseointegração ${ }^{1}$.

O sucesso da osseointegração depende muito do tipo de interface obtida entre implante e osso. Tal interface deve viabilizar a transmissão homeostática das forças oclusais, as quais são muito bem absorvidas e transmitidas pelos implantes osseointegrados ${ }^{2}$. Observa-se que os implantes com tratamento de superfície apresentam maior velocidade de osseointegração quando comparados com os de superfície lisa ${ }^{3-8}$.

Partindo desse princípio, em 2007, a superfície Nanotite ${ }^{\circledast}$ foi introduzida no mercado apresentando uma nanotopografia criada por uma discreta deposição cristalina de nanopartículas de fosfato de cálcio $(\mathrm{CaP})$ sobre a superfície do implante Osseotite ${ }^{\circledR}$ (BIOMET $3 i^{\mathrm{TM}}$ - superfície duplamente condicionada por ácido. Esse aprimoramento, quando avaliado em escala nanométrica, mostra melhoria nos resultados quanto à velocidade de osseointegração em comparação aos grupos que utilizaram a superfície Osseotite $^{\circledR}$, não só em modelo animal, mas também no estudo em seres humanos ${ }^{9}$.

As indicações para o uso dos implantes com superfície Nanotite ${ }^{\circledast}$ são para protocolos de carga imediata, colocação imediata pós-extração, inserção simultânea de implantes e enxertos ósseos, áreas estéticas em que a preservação óssea é crítica e em localizações que requeiram implantes curtos ${ }^{10}$.

No intuito de avaliar-se a estabilidade do implante após a sua instalação, tem-se preconizado a utilização da AFR, instrumento que fornece medidas objetivas e confiáveis de micromobilidade lateral em várias fases do tratamento com implantes. $\mathrm{O}$ método analisa, inicialmente, a frequência de ressonância de um pequeno transdutor (Smartpeg) aparafusado ao implante ou ao pilar protético. A unidade de medida utilizada, atualmente, é o implant stability quocient (ISQ), cuja tradução significa "quociente de estabilidade do implante", que fora primeiramente aferido em Hertz (Hz). O quociente de estabilidade do implante é um mapeamento linear de frequência de ressonância medido em $\mathrm{kHz}$ (quilohertz), mas, para tornar-se clinicamente víavel, foi transformado em escala de 1-100 ISQ. Quanto maior for o ISQ, mais estável será o implante. Dessa forma, há indicações de que a estabilidade aceitável situa-se entre 55 e 85 ISQ, com um nível médio de $70 \mathrm{ISQ}^{11}$.

Ainda que os tratamentos de superfície dos implantes facilitem a osseointegração, existe um processo inflamatório no reparo ósseo perimplantar que pode ser dividido em fase aguda (relativamente curta, com duração de minutos, horas ou alguns dias) e fase crônica (exsudação de líquido e proteínas plasmáticas, edema e migração de leucócitos predominantemente neutrófilos). A segunda fase é a mais longa, e também estão associadas à presença de linfócitos, plasmócitos e macrófagos a proliferação de vasos sanguíneos, a fibrose e a necrose tecidual $^{12}$. Para promover uma minimização dos efeitos inflamatórios, tem-se utilizado a terapia a laser de baixa potência (LLLT). A grande vantagem obtida com esse instrumento está relacionada ao tratamento da dor pós-operatória, reduzindo-se, assim, o uso de drogas analgésicas. Tal fato torna-se relevante, na medida em que possibilita a redução na prescrição excessiva de produtos farmacêuticos que podem trazer efeitos colaterais negativos e prejudiciais, especialmente na população de terceira idade. Portanto, a laserterapia tornou-se uma alternativa eficaz ou coadjuvante no intuito de se alcançar melhores resultados clínicos ${ }^{13}$.

Em contrapartida, os efeitos fotoquímicos, fotofísicos e fotobiológicos gerados pela luz do laser afetam não somente a área sob aplicação, como também regiões mais profundas ${ }^{14}$. Sabe-se que a biomodulação promovida pelo laser em células no local de sua aplicação pode ocorrer, igualmente, em tecidos ou órgãos distanciados do ponto de irradiação inicial ${ }^{15}$.

Embora a LLLT tenha se tornado uma prática comum nas diversas áreas biomédicas, ainda não há um entendimento claro sobre seus possíveis efeitos colaterais. Estudos pertinentes à utilização do laser de emissão infravermelha sobre a glândula tireoide têm demonstrado um aumento na atividade mitótica de células foliculares, hiperatividade transitória em alguns folículos ${ }^{16,17}$ e alterações dos níveis hormonais de tri-iodotironina $\left(\mathrm{T}_{3}\right)$ e tiroxina $\left(\mathrm{T}_{4}\right)$ circulantes no soro sanguíneo ${ }^{18}$.

Estudos recentes preferem utilizar o modelo animal coelho, pois o reparo ósseo nesse tipo amostral leva, aproximadamente, 42 dias e em seres humanos requer de 4 a 6 meses, até que se torne maduro e resistente, para então poder receber carga sem comprometimento da estabilidade inicial do implante. Alguns trabalhos indicam que a maturação óssea perimplantar deve-se ao aumento de deposição de hidroxiapatita de cálcio pelos osteoblastos irradiados pela laserterapia de baixa potência. Após a sua irradiação, é possível reduzir o tempo de colocação de carga sobre os implantes na mandíbula 
de humanos de 4 meses para cerca de 2 meses e 24 dias, e na maxila, de 6 meses para 4 meses e 6 dias, pela aceleração do processo de cicatrização óssea perimplantar ${ }^{19-23}$.

Para avaliação do efeito da LLLT, podem-se utilizar as análises histológicas e histomorfométricas por diversas colorações. As avaliações do reparo ósseo e da resposta inflamatória são passíveis de serem evidenciadas por meio da técnica de coloração histológica por hematoxilina-eosina (HE). A análise da presença de fibras colágenas, bem como o padrão de sua distribuição nas regiões de periósteo, endósteo, medula e nas zonas de transição periósteo-medular e endósteo-medular pode ser realizada pela técnica de coloração histológica picrosirius-red ${ }^{24}$. Além disso, é possível realizar imagens por tomografias computadorizadas de feixe cônico (TCFC) com o objetivo de estudar a interface entre osso e implante im-27. $^{25}$.

Outro método de avaliação utilizado é a microscopia eletrônica de varredura (MEV), por fornecer, rapidamente, informações sobre a morfologia e a identificação de elementos químicos de uma amostra sólida. Os aparelhos modernos permitem aumentos de 300.000 vezes de magnificação, conservando a profundidade de campo compatível com a observação de superfícies rugosas, assim como uma alta definição de imagem, estando no espectro de 1-5 nanômetros. Ainda, empregando-se o método espectrometria por dispersão de energia (EDS), que compõe esse microscópio, tem-se a possibilidade de identificar, em determinados pontos das amostras analisadas, a composição química desses materiais $^{28}$

O objetivo desta comunicação preliminar é descrever a técnica cirúrgica e a sequência laboratorial utilizada na obtenção de dados por meio de dosagem hormonal, AFR, TCFC, MEV, EDS, análise histológica e histomorfométrica da região perimplantar pós-terapia com laser não ablativo (LLLT) em modelo experimental coelho.

\section{Materiais e método}

Este estudo foi aprovado pela Comissão de Ética no Uso de Animais da Pontifícia Universidade Católica do Rio Grande do Sul (PUCRS), Brasil, sob protocolo $n^{\circ}$ 11/00235 (21 de julho de 2011), e pela Comissão de Ética no Uso de Animais do Hospital de Clínicas de Porto Alegre (CEUA/HCPA), sob protocolo $\mathrm{n}^{\circ}$ 11-0449 (21 de dezembro de 2011). Nesta pesquisa, foram observados os Princípios Éticos para Experimentação em Animais, que constam na Lei 11.794, de 08 de outubro de 2008 (Lei Arouca), que regulamenta e estabelece procedimentos para o uso científico de animais, revogando a Lei 6.638, de 8 de maio de 1979; respeitando-se, também, os Princípios Éticos na Pesquisa Experimental, determinados pelo Colégio Brasileiro de Experimentação Animal.
A amostra foi composta por 40 coelhos da ordem Lagomorpha, gênero Oryctolagus, espécie Oryctolagus cuniculus, raça Nova Zelândia, variedade branco, machos, com três meses de idade, pesando entre 3 e $4 \mathrm{~kg}$. Os animais foram divididos em cinco grupos com oito coelhos cada, sendo três grupos designados como experimentais (EI, EII e EIII) e dois como controle (CI e CII - animais não irradiados).

Após a aferição do peso, na sala de pré-anestesia, 32 animais foram anestesiados por meio de injeção intramuscular de Dopalen ${ }^{\circledR}$ (Cloridrato de Ketamina, fabricado por Divisão Vetbrands Saúde Animal, São Paulo/SP), na dose de $40 \mathrm{mg} / \mathrm{kg}$ de peso, e de Anasedan ${ }^{\circledR}$ (Cloridrato de Xilasina, fabricado por Divisão Vetbrands Saúde Animal, São Paulo/SP), $3 \mathrm{mg} / \mathrm{kg}$ de peso. Após dez minutos, foi realizada a antissepsia da região do incisivo inferior esquerdo com digluconato de clorexidina a $2 \%$ (FGM Produtos Odontológicos, Joinville/SC). A seguir, deu-se início ao procedimento cirúrgico, realizando-se, na região do incisivo inferior esquerdo, uma infiltração de $0,5 \mathrm{ml}$ de lidocaína a $2 \%$ (Probem Laboratório de Produtos Farmacêuticos e Odontológicos Ltda.) com epinefrina na proporção de 1:100.000 visando à vasoconstrição local (Figura 1). Em seguida procedeu-se à sindesmotomia, luxação e exodontia do incisivo inferior esquerdo com auxílio de fórceps infantil nº 5 (Figura 1).

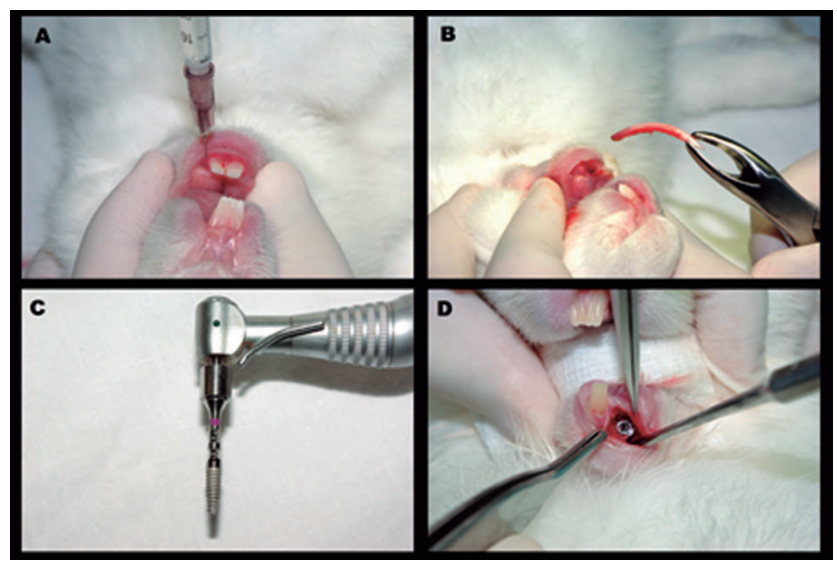

Figura 1 - Procedimento cirúrgico de extração do dente incisivo inferior esquerdo em modelo experimental coelho. A) infiltração anestésica com lidocaína $2 \%$ associada a epinefrina 1:100.000 visando à vasoconstrição local; B) extração do incisivo; C) implante Nanotite ${ }^{\circledR}(3,25 \times 11,5 \mathrm{~mm})$ posicionado para colocação com contra-ângulo redutor $20: 1 \cdot D$ vista oclusal do implante colocado no alvéolo do incisivo inferior recém-extraído.

Sob irrigação abundante do alvéolo com solução salina de soro fisiológico $0,9 \%$ foi realizada a colocação de um implante osseointegrado de $3,25 \mathrm{~mm}$ de diâmetro por $11,5 \mathrm{~mm}$ de comprimento, cônico, autorrosqueável, com superfície Nanotite ${ }^{\circledR}$ (Implante Nanotite ${ }^{\circledR}$ - BIOMET3i - 4555, Riverside Drive - Palm Beach Gardens, FL), comercialmente disponível e adquirido especialmente para esta pesquisa junto à empresa Odontodis ${ }^{\circledR}$ (representante oficial de Biomet 3i para o Rio Grande do Sul) (Figura 1). 
Procedeu-se a fresagem gradativa, intermitente e precisa do alvéolo, seguindo a sequência de fresas preconizada pelo fabricante - Biomet $3 \mathrm{i}^{\oplus}$, na velocidade de $1200 \mathrm{rpm}$ e torque de $30 \mathrm{~N} / \mathrm{cm}$, usando um contra-ângulo redutor de 20:1, modelo Koncept da marca $\mathrm{KaVo}^{\circledR}$ (Fábrica KaVo do Brasil Ind. Com. Ltda., Joinville/SC), conectado ao motor elétrico digital Driller ${ }^{\circledR}$ (Jaguaré/SP), modelo BLM 600, com uma constante e intensa irrigação externa usando solução fisiológica estéril de cloreto de sódio a 0,9\%, de modo a evitar o aquecimento do tecido ósseo.

Sequência: Fresa com ponta em forma de lança para marcação inicial da perfuração $\left(\mathrm{ACT}^{\circledR}\right.$ Pointed Starter Drill -ACTPSD). Fresa com formato helicoidal de 2,0 mm de diâmetro (2mm Twist Drill) com penetração de $11,5 \mathrm{~mm}$ (comprimento dos implantes). Fresa com formato cônico de $3,25 \mathrm{~mm}$ de diâmetro (3.25 mm Quad Shaping Drill - QSD3211) com penetração de $11,5 \mathrm{~mm}$ (comprimento dos implantes). Inserção do implante Nanotite ${ }^{\circledR}$ com 3,25 mm de diâmetro por 11,5 mm de comprimento, utilizando montador específico (Handpiece Connector - MDR10) para inserção com o contra-ângulo, na velocidade de $20 \mathrm{rpm}$ e com o torque de inserção de $30 \mathrm{~N}$ (Figura 1).

Após a inserção do implante, foi instalado o transdutor (Smartpeg) para aferição da frequência de ressonância, tendo sido obtidas quatro medidas (vestibular, lingual, mesial e distal) de ISQ com utilização do aparelho Osstell ${ }^{\circledR}$ (Osstell AB, Gamlestadsvägen 3B, SE 415 02, Göteborg, Sweden) (Figura 2).

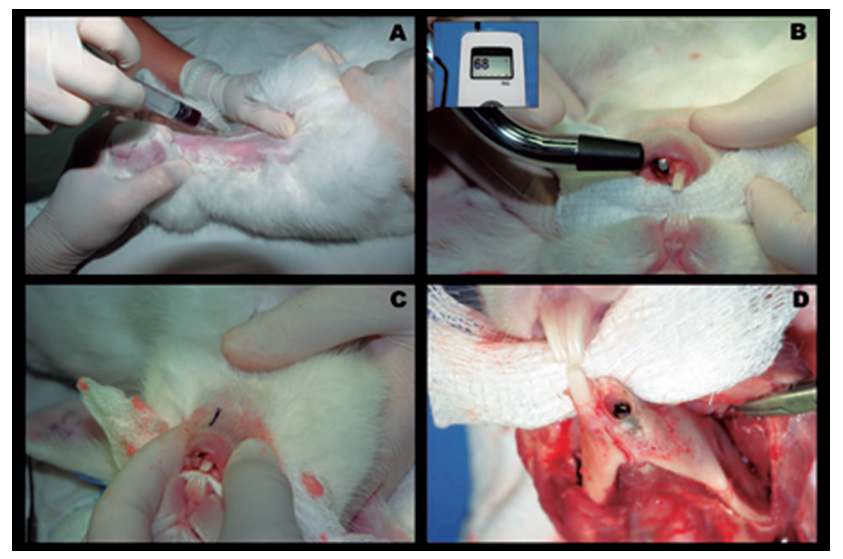

Figura 2 - Procedimentos realizados durante a metodologia proposta. A) coleta de sangue da veia jugular do coelho; B) registro do ISQ por meio de aparelhagem específica (Osstell ); C) marcação do longo eixo do implante, visando a facilitar a aplicação do laser; D) dissecação da mandíbula e exposição da área operada.
Uma vez obtidas as medidas de estabilidade (ISQ), o Smartpeg foi removido, sendo instalado o parafuso de cobertura dos implantes e suturado o leito cirúrgico com um fio agulhado mononylon Ethicon 4- $0^{\circledast}$ (fio monofilamentado 4.0, agulha Ethiplast E-16 com curvatura de 3/8 e comprimento de 1,65 cm, fabricado pela Ethicon, Johnson \& Johnson, New Jersey, EUA). Aproveitou-se a anestesia geral para tricotomizar por raspagem dos pelos e tatuar com caneta dermográfica (Codman ${ }^{\circledR}$, Johnson \& Johnson, New Jersey, EUA) a região correspondente ao longo eixo do implante nos animais dos grupos experimentais, no intuito de identificar o local da irradiação com o laser (Figura 2). A sutura foi removida após sete dias em todos os animais.

Todos os animais receberam, imediatamente após o término dos procedimentos cirúrgicos, a terapia medicamentosa composta de analgésico com Tramadol ${ }^{\circledR}$ (Cloridrato de Tramadol 50 mg Inj. União Química, Embu-Guaçu/SP, Brasil), aplicado via intramuscular, $5 \mathrm{mg} / \mathrm{kg}$, no pós-operatório imediato, e uma segunda dose após 24 horas. Para o controle de possíveis infecções pós-operatórias, utilizou-se Enrofloxacina ${ }^{\circledR}$ (Zelotril 10\% Agener União, Embu-Guaçu/SP, Brasil), aplicado via intramuscular, $5 \mathrm{mg} / \mathrm{kg}$, uma vez ao dia, durante três dias.

As técnicas de coleta de sangue e as aplicações de LLLT serão descritas, respectivamente, no protocolo para dosagens hormonais e no protocolo para aplicação da terapia laser de baixa potência.

No $45^{\circ}$ dia do experimento, ou seja, decorridos 30 dias da última sessão de laserterapia, os animais foram mortos após a sedação (mesmo protocolo utilizado na etapa cirúrgica) com administração de uma sobredose anestésica de Propofol ${ }^{\circledR}$ (Lipuro 1\% $10 \mathrm{mg} / \mathrm{mL}$, Laboratórios B. Braun SA, São Gonçalo/ RJ, Brasil), na dose de $1 \mathrm{~mL} / \mathrm{kg}$, e posterior parada cardíaca provocada por $\mathrm{KCl} 10 \%$ (cloreto de potássio, Isofarma Industrial Farmacêutica Ltda., Precabura Eusébio/CE, Brasil), na dose de $1 \mathrm{~mL} / \mathrm{kg}$.

Foi instalado sobre os implantes o transdutor (Smartpeg) para aferição da frequência de ressonância, e foram obtidas, novamente, quatro medidas (vestibular, lingual, mesial e distal) de ISQ, mediante utilização do aparelho Osstell ${ }^{\circledR}$.

Após a aferição das medidas de ISQ final, as mandíbulas dos animais foram dissecadas (Figura 2) e armazenadas em formol neutro tamponado a $10 \%$, para fins de processamento e preparo das amostras para análise por TCFC, MEV, EDS, histológica e histomorfométrica. (Tabela 1) 


\begin{tabular}{l|l|c}
\hline \multicolumn{1}{c|}{ Grupo } & \multicolumn{1}{c}{ Procedimento } \\
\hline Cl (Grupo Controle Hormonal) & Sem exodontia e sem laser \\
CII (Grupo Controle Hormonal e Histológico) & Exodontia + implante \\
El (Grupo Experimental) & Exodontia + implante + laser \\
EII (Grupo Experimental) & Exodontia + implante + laser \\
EIII (Grupo Experimental) & Exodontia + implante + laser \\
\hline
\end{tabular}

\section{Protocolo para dosagens hormonais}

Coletou-se $3 \mathrm{~mL}$ de sangue dos 40 coelhos por punção venosa da veia jugular (Figura 2). O sangue coletado foi acondicionado em tubos Vacutainer $^{\circledR}$ (BD-Vacutainer ${ }^{\circledR}$, Pediatric Systems, Becton \& Dickinson $\mathrm{Co}$ ) sem anticoagulantes e identificados individualmente, originando uma amostra para cada animal dos cinco grupos.

Realizou-se, então, a centrifugação de todas as amostras em centrífuga específica (Centrífuga de Bancada Excelsa ${ }^{\circledR}$ Modelo 280, FANEM Ltda., São Paulo/SP, Brasil), durante 15 minutos, a 2.700 rpm, sob temperatura e pressão constantes. Posteriormente, por meio de pipetagem de precisão, realizou-se a separação do soro e deposição em Eppendorf ${ }^{\circledR}$ (Eppendorf do Brasil Ltda., São Paulo/SP, Brasil). O soro foi, então, enviado, sob refrigeração, ao Laboratório de Análises Clínicas Veterinárias da Universidade Federal do Rio Grande do Sul (LacVet UFRGS, Porto Alegre, Brasil) para realização das dosagens de tri-iodotironina $\left(\mathrm{T}_{3}\right)$, tiroxina $\left(\mathrm{T}_{4}\right)$, cálcio e albumina séricos.

As dosagens de tri-iodotironina $\left(\mathrm{T}_{3}\right)$, tiroxina $\left(\mathrm{T}_{4}\right)$, cálcio e albumina foram realizadas em todos os animais dos cinco grupos, por meio de coleta de sangue 72 horas antes dos procedimentos cirúrgicos, a fim de servirem de controle pré-aplicação do laser.

No dia do procedimento cirúrgico, após extração do incisivo, instalação do implante e aplicação da laserterapia nos grupos EI, EII, EIII, foi realizada a segunda coleta de sangue em todos os animais dos cinco grupos.

Setenta e duas horas após a primeira sessão de laserterapia nos grupos experimentais, foi realizada a terceira coleta de sangue em todos os animais. Também 72 horas após a última sessão de laserterapia nos grupos experimentais, foi realizada a quarta e última coleta de sangue para as dosagens de $\mathrm{T}_{3}, \mathrm{~T}_{4}$, cálcio e albumina em todos os animais dos cinco grupos.

Os resultados obtidos foram anotados em tabelas para posterior avaliação e análise estatística.

\section{Protocolo para aplicação da terapia a laser de baixa potência}

Foi utilizado o aparelho TheraLase ${ }^{\circledast}$ (DMC Equipamentos, São Carlos, São Paulo), com laser de diodo infravermelho com meio ativo GaAlAs (arseneto de gálio e alumínio), comprimento de onda de $830 \mathrm{~nm}$, de forma pontual (Figura 3), potência de $50 \mathrm{~mW}$, no modo de emissão contínua, a cada 48 horas, num total de sete sessões de aplicação, durante treze dias e com três doses distintas para os grupos experimentais (Tabela 2). Os animais não irradiados (grupo controle - CI e CII) foram submetidos a uma simulação da irradiação com o aparelho desligado, passando pela mesma rotina dos animais irradiados.

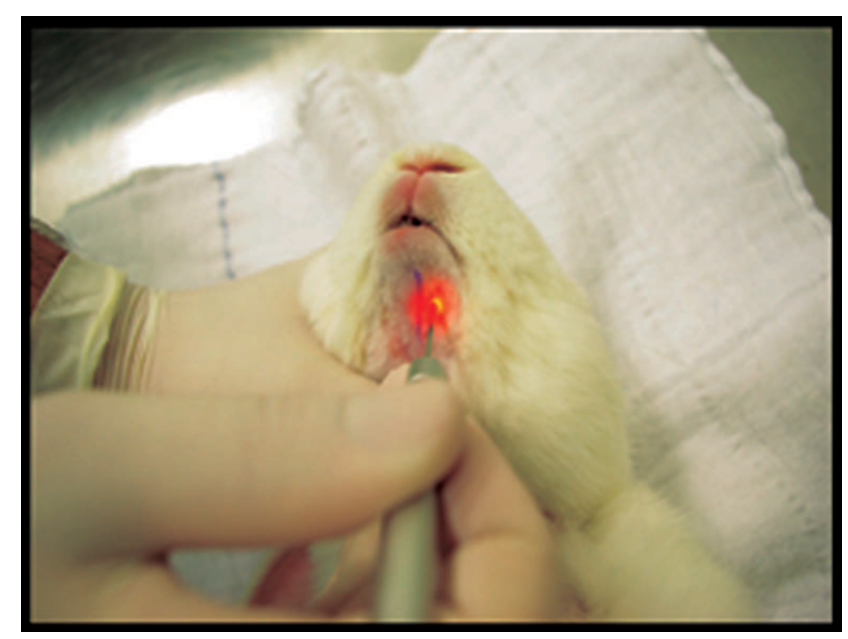

Figura 3 - Aplicação da ponteira do aparelho de LLLT à lateral e à medial da marcação, a qual representa o longo eixo do implante inserido em sínfise mandibular do lado esquerdo. Notar o cuidado para que a luz do laser não se sobreponha à marcação feita com caneta, o que poderia resultar num viés à pesquisa. 
Tabela 2 - Parâmetros da LLLT

\begin{tabular}{|c|c|c|c|c|}
\hline Parâmetros & $\mathrm{Cl} / \mathrm{Cll}$ & El & EII & EIII \\
\hline Tipo de luz laser & - & GaAlAs & GaAlAs & GaAlAs \\
\hline Potência (mW) & - & 50 & 50 & 50 \\
\hline Comprimento de onda (nm) & - & 830 & 830 & 830 \\
\hline Modo de emissão & - & contínuo & contínuo & contínuo \\
\hline Pontos de irradiação & 0 & 2 & 2 & 2 \\
\hline № de aplicações por ponto & 0 & 1 & 1 & 1 \\
\hline Energia por ponto $\left(\mathrm{J} / \mathrm{cm}^{2}\right)$ & 0 & 5 & 2.5 & 10 \\
\hline Densidade total de energia por sessão $\left(\mathrm{J} / \mathrm{cm}^{2}\right)$ & 0 & 10 & 5 & 20 \\
\hline Tempo de irradiação por ponto (segundos) & 0 & 101 & 51 & 201 \\
\hline Dose total $\left(\mathrm{J} / \mathrm{cm}^{2}\right)$ & 0 & 70 & 35 & 140 \\
\hline
\end{tabular}

\section{Protocolo para aquisição das medidas de frequência de ressonância}

Outra análise estudada nesta metodologia foi a frequência de ressonância, a qual é considerada um método não invasivo para mensuração da estabilidade do implante.

Como método diagnóstico, o Osstell ${ }^{\circledR}$ permite ao cirurgião-dentista otimizar as fases de cicatrização do implante, da reconstrução protética e do protocolo cirúrgico, podendo diminuir o processo a apenas uma fase cirúrgica, por ser capaz de fornecer medições repetidas de estabilidade do implante na colocação, durante a cicatrização e após o carregamento, permitindo detectar instabilidade do implante e tomar as medidas adequadas para evitar falha, ou, ao menos, resgatar um implante antes que esta ocorra ${ }^{29}$.

A medida da estabilidade inicial dos implantes foi realizada após a sua inserção no alvéolo por meio da instalação de um transdutor (Smartpeg) sobre o implante (Figura 2) para aferição da frequência de ressonância - sendo obtidas quatro medidas para cada implante (vestibular, lingual, mesial e distal) de ISQ (Implant Stability Quotient) com utilização do aparelho Osstell ${ }^{\circledR}$, de forma que a ponteira do aparelho foi posicionada perpendicularmente ao transdutor e recalibrada após cada aferição. Esse mesmo protocolo de aferição foi realizado após a morte dos animais, previamente à dissecação das mandíbulas dos 32 coelhos (Figura 2).

\section{Protocolo para aquisição das imagens tomográficas}

As mandíbulas dissecadas, e sem tecido mole, dos 32 coelhos foram submetidas ao exame TCFC para análise dos valores dos níveis de cinza em relação à área perimplantar.

$\mathrm{O}$ equipamento utilizado para aquisição das imagens foi o K9000c 3D Cone Beam CT Scanner da marca Kodak ${ }^{\circledast}$ (Kodak Carestream Health, São Paulo/SP, Brasil). Utilizou-se como protocolo de aquisição os seguintes parâmetros: voxel de 100 $\mu \mathrm{m}$, resolução de 10 pixels por milímetro, tensão de pico de $60 \mathrm{k}$, corrente de $10 \mathrm{~mA}$, tempo de exposição de 10,8 s e área de aquisição (FOV) de 50 x 38 mm.

As imagens foram adquiridas e armazenadas no protocolo Digital Imaging and Communications in Medicine (DICOM) e, posteriormente, reconstruídas e analisadas no software livre Image J (Freeware - software de domínio público desenvolvido pelo National Institute of Health), com o qual foi possível analisar a densidade da imagem, relacionando os limites de atenuação dos feixes de raios X com os valores de níveis de cinza na área perimplantar dos coelhos operados na aquisição tomográfica.

Para a reconstrução e o processamento no software Image J, as imagens foram convertidas para 8 bits (256 níveis de cinza), definindo-se uma escala de 0 a 255 em cada imagem, onde 0 representa valores escuros dentre os níveis de cinza da imagem (correspondente a menor atenuação dos feixes de raios $\mathrm{X}$ no momento da exposição) e 255 representa valores claros a brancos dentre os níveis de cinza (maior atenuação dos feixes de raios $\mathrm{X}$ ), dependendo do tipo do tecido irradiado.

Como as imagens foram adquiridas em um processo volumétrico, para fins de determinação e limitação das regiões para análise, todas as sequências foram reconstruídas no software Image $\mathrm{J}$ em plano sagital.

$\mathrm{Na}$ análise dos níveis de cinza, correlacionados com o processo de atenuação e absorção dos raios $\mathrm{X}$ nas aquisições (densidade de imagem), foram selecionadas regiões de interesse (ROIs), no local entre as espiras 5,6 e 7 .

Foram utilizadas duas metodologias de delimitação das ROIs para avaliação entre técnicas de análise: duas ROIs para avaliação linear em 2,5 $\mathrm{mm}$ na face vestibular e lingual do implante e duas outras para avaliação da área perimplantar com ROIs retangulares $(2,5 \times 1,2 \mathrm{~mm})$ na face vestibular e lingual do implante (Figura 4). 


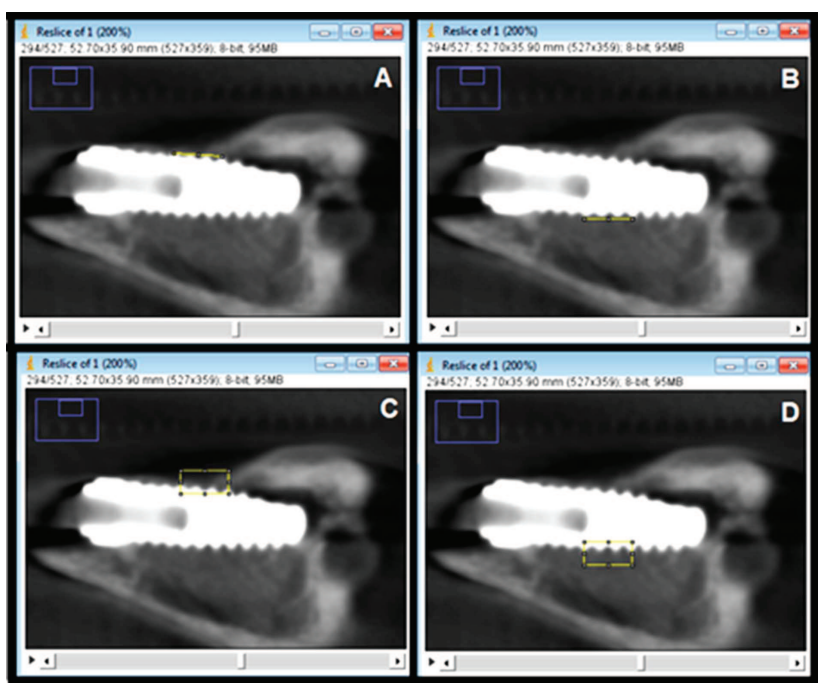

Figura 4 - Delimitação das regiões de interesse (ROIs) entre as espiras 5, 6 e 7 para as análises: duas ROIs para avaliação linear ( $A$ e B) na face vestibular e lingual do implante e duas para avaliação da área perimplantar (C e D) com ROls retangulares nas mesmas faces do implante.

\section{Protocolo de preparo das amostras para análise histológica e histomorfométrica}

Após a aquisição das imagens tomográficas, 24 peças foram submetidas ao processo de desidratação em uma série de banhos: $1^{\circ}$ banho - álcool $70 \%$ durante sete dias; $2^{\circ}$ banho - álcool $80 \%$ durante sete dias; $3^{\circ}$ banho - álcool $90 \%$ durante sete dias; $4^{\circ}$ banho - álcool absoluto durante sete dias. Posteriormente, realizou-se a infiltração da resina LR White ${ }^{\circledR}$ - médium grade (LR White Embedding Resin Kit: Medium grade, EMScience, Hatfield, PA, Estados Unidos) e polimerização em forno convencional, por 24 horas, a $60^{\circ} \mathrm{C}$ (Figura 5).

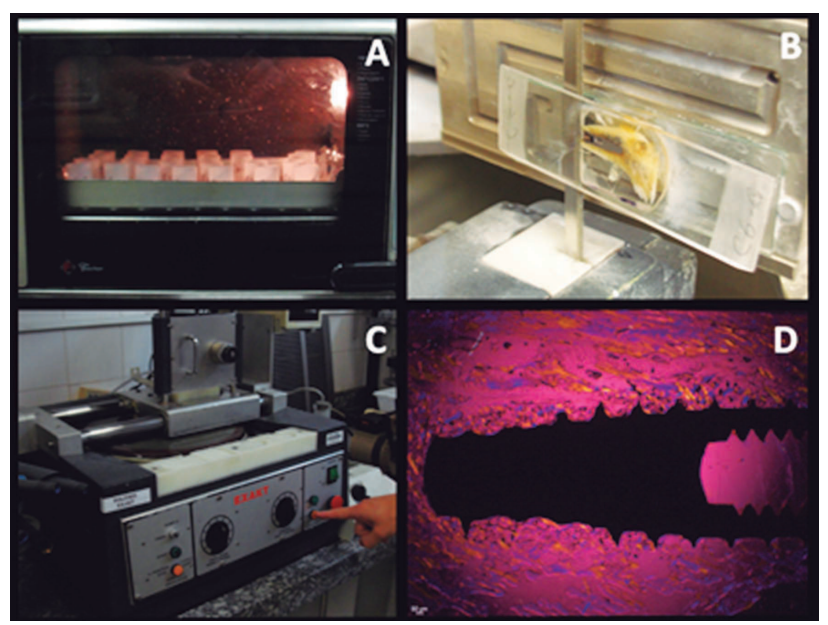

Figura 5 - Preparo para histomorfometria. A) termopolimerização da resina utilizada para preparo das amostras a $60^{\circ} \mathrm{C}$ por 24 horas; B) corte das lâminas em micrótomo EXAKT $T^{\circledR}$ - espessura de $200 \mu \mathrm{m}$; C) desgaste e polimento das amostras em politriz EXAKT ${ }^{\circledR}$ - espessura de $30 \mu \mathrm{m}$; D) visualização em microscópio ótico imediatamente após o final do polimento.
Após, as peças foram cortadas em micrótomo para tecido duro EXACT Diamond Band Saw com fitas impregnadas por partículas de diamante (Diamond Cutting Band, 0,2 mm, D64, EXACT, Nordestedt, Schleswing-Holstein, Alemanha), em velocidade calibrada, até chegar à região de interesse para análise (Figura 5). Após esse corte, as peças passaram por um processo de polimento em equipamento próprio EXACT Grinding System, com lixas de granulação em ordem crescente, $800,1.200$ e 2.000 (Polishing Paper K2000, EXACT, Nordestedt, Schleswing-Holstein, Alemanha) (Figura 5).

As lâminas foram coradas com hematoxilina-eosina, picrossírius-red e azul de toluidina e aderidas a lamínulas para análise. As imagens foram analisadas em microscópio ótico em aumentos de 40, 100 e $400 \mathrm{X}$ (Olympus BX51 ${ }^{\circledR}$, Olympus Corporation, Japão), capturadas por meio de uma câmera fotográfica digital (Olympus U-TV0.5XC-3), acoplada ao microscópio de luz, e armazenadas em arquivo TIFF (.tif), utilizando o software Qcapture Pro com resolução de imagem de 2560x1920 (full frame) e 36 bits de cor por pixel.

As análises histométricas foram realizadas por meio do software de análise de imagens IMAGELAB $2000^{\circledR}$, versão 2.4. Foram calculadas, em porcentagem, a extensão linear de contato entre o tecido ósseo e a superfície do implante (ELCOI) e a área de tecido ósseo presente (AO) entre as três espiras localizadas no terço médio do implante bilateralmente.

\section{Protocolo de preparo das amostras para avaliação por MEV}

As peças restantes receberam preparo específico para avaliação por MEV. Tal preparação consistiu, inicialmente, da desidratação em diferentes concentrações de álcool $(60 \%, 70 \%, 80 \%$ e $90 \%)$ e da inclusão em resina (EMBed-812 Embedding Kit. EMSDIASUM $^{\circledR}$, Hatfield, Filadelfia, EUA) termoquimicamente ativada - específica para esse tipo de análise -, colocando-se as amostras em pequenos frascos, rigorosamente identificados. Assim sendo, as amostras foram polimerizadas em um forno convencional a $60^{\circ} \mathrm{C}$, por 48 horas. Posteriormente, as amostras foram removidas desses frascos e posicionadas em uma serra (Logithed AXL1 ANNULAR SAW, Materials Technologists \& Engineers, Glasgow, Escócia, Reino Unido) a 1.000 rpm, a fim de receberem um corte no longo eixo do implante, separando as peças em duas metades, de modo a permitir a visualização do conjunto osso-implante no seu longo eixo com as corticais alveolar e basilar da mandíbula das amostras. Dessa forma, as peças apresentando implantes seccionados no seu longo eixo, circundados por osso, passaram por fases de lixamento (lixas d'água de granulações variando de 220 a 4.000) e polimento (através de feltro e solu- 
ção de alumina contendo grãos de 1 um a 0,25 um). Finalmente, antes da avaliação no microscópio eletrônico de varredura, as peças foram secas em uma dessecadora a vácuo com gel de sílica por duas semanas e metalizadas com uma superfície em ouro em metalizadora específica (BAL-TEC SCD 050 Sputter Coater, Capovani Brothers Inc., Nova Iorque, EUA) (Figura 6)

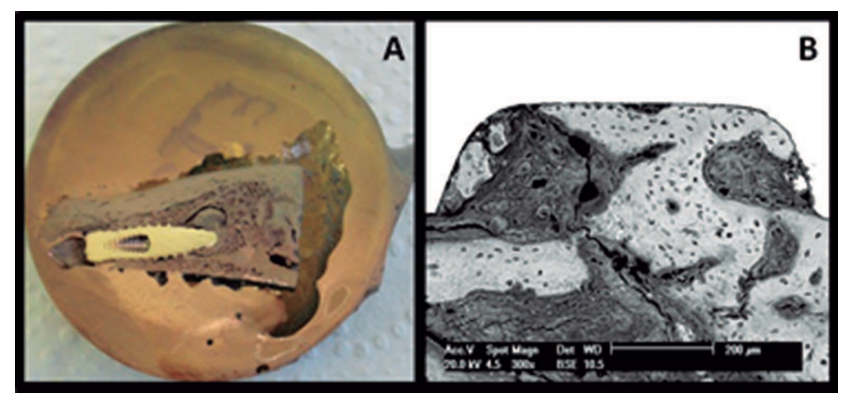

Figura 6 - Preparo para MEV. A) peça metalizada para visualização em microscopia eletrônica - visualização total do implante imerso em tecido ósseo; B) interface osso-implante-aumento de 300 x na região do corpo do implante - íntimo contato entre as superfícies e a identificação das regiões ósseas: medular e cortical.

As observações no microscópio eletrônico de varredura (Microscópio Philips ${ }^{\circledR}$, modelo XL 30 FEG EDX, Eindhoven, Holanda) foram feitas em magnificações de 25 x, 50 x, 250 x e 300 x, com objetivo de avaliar-se a interação da superfície de contato entre osso e implante (Figura 6), assim como da composição química do tecido neoformado nessa região, por meio do EDS.

\section{Discussão}

O uso de modelo animal coelho tem sido observado na literatura para avaliação da aplicação da terapia a laser de baixa potência sobre implantes dentários colocados em tíbias ${ }^{19,30-33}$. No entanto, nesta pesquisa, procurou-se simular as condições de instalação do implante após a extração dentária em mandíbula de coelhos. Esse método possibilitou maior confiabilidade, pois o osso mandibular alveolar sofre uma carga mastigatória diferente da carga sofrida pela tíbia de coelhos ${ }^{34}$. Dessa forma, buscou-se colocar os implantes nos alvéolos após extração dentária, pois é a condição mais próxima de uma situação clínica normal.

Para determinar os efeitos hormonais sobre a densidade óssea durante o crescimento ósseo, pesquisadores têm utilizado coelhos Nova Zelândia brancos, em razão do seu curto período de desenvolvimento e remodelamento ósseo acelerado em comparação aos primatas ${ }^{35}$. Esse modelo animal tem sido popularmente utilizado para avaliação do imbricamento ósseo no interior de implantes dentários e da interface osso-implante ${ }^{36}$.

A LLLT vem sendo mostrada como uma importante ferramenta na bioestimulação tecidual quan- do do processo cicatricial de uma ferida ou dano cirúrgico. A interação do laser no tecido é determinada pela composição de seu meio ativo, comprimento de onda, densidade de energia e de potência, forma de emissão do laser (contínua, pulsada ou desencadeada); taxa e duração da pulsação, utilização ou não de fibras de contato, tipo de raio (focado ou desfocado), quantidade de energia depositada no tecido, do número de sessões e das características óticas do tecido, como os coeficientes de absorção e espalhamento ${ }^{12,37}$.

O uso correto e apropriado desses parâmetros tem mostrado a efetividade da laserterapia na promoção da bioestimulação na cicatrização óssea. Para tal, é necessário um protocolo bem definido que garanta o resultado esperado para cada terapia proposta $^{12,20,37-39}$.

Estudos demonstram que a aplicação da LLLT favorece o reparo ósseo na região de implantes dentários. Essa irradiação com laser tem efeito positivo nos estágios inicias da osseointegração. Em estudo realizado em coelhos submetidos a terapia a laser de baixa potência, observou-se um aumento significativo nos valores de torque de remoção dos implantes nos grupos, quando comparados com os grupos controle ${ }^{30}$. A LLLT promove a osseointegração de implantes com estabilidade inicial pobre, especialmente nos estágios primários de cicatrização óssea ${ }^{19-23,30,33,40,41}$.

Os protocolos para a utilização dos laseres, em diversos procedimentos clínicos, estão sendo investigados, pois nem todas as suas atuações e seus efeitos sistêmicos estão esclarecidos. A LLLT pode atuar nas funções endócrinas, comprovando os possíveis efeitos do laser sobre as glândulas secretoras $^{42,43}$. Assim, buscou-se, com essa metodologia, avaliar os efeitos sistêmicos do laser por meio de coletas de sangue no momento anterior à aplicação e em períodos de 72 horas após a laserterapia.

A estabilidade do implante desempenha um papel importante no sucesso da osseointegração. A estabilidade primária constitui um fenômeno mecânico que está relacionado à qualidade e à quantidade óssea local, ao tipo de implante e à técnica de colocação utilizada. A estabilidade secundária, por sua vez, corresponde ao aumento da estabilidade atribuível à formação e à remodelação óssea na interface entre implante e osso. Técnicas para medir a estabilidade do implante e a osteointegração têm sido alvo de discussão, pois se trata de um critério significativo para avaliar o sucesso dos implantes dentários. Métodos quantitativos, incluindo a análise de frequência de ressonância, podem fornecer informações valiosas relacionadas ao prognóstico do implante osseointegrado ${ }^{44}$.

Partindo de tal princípio, busca-se, a partir dessa metodologia, utilizar esse meio de análise não invasivo da estabilidade inicial entre osso e implante. A RFA, como uma técnica disponível comercialmente, permitiu medir a estabilidade da peça em unida- 
des de ISQ, em qualquer momento, durante o curso do tratamento com implantes. Esses valores de ISQ são derivados da rigidez do sistema osso/implante e da calibração dos parâmetros do transdutor. Cada transdutor é calibrado pelo seu respectivo fabricante, levando a que todas as medições sejam diretamente comparáveis. Um valor elevado do ISQ, ou seja, próximo a 100, indica alta estabilidade, enquanto um baixo valor, próximo a zero, indica baixa estabilidade do implante ${ }^{45}$.

Pesquisadores avaliaram a relação entre a posição da ponteira do aparelho de frequência de ressonância, o diâmetro do implante, o torque de inserção do implante e a perda óssea perimplantar. Os resultados observados demonstraram que os valores de ISQ não foram afetados pela direção da ponteira (paralela ou perpendicular ao longo eixo do implante). O diâmetro do implante, da mesma forma, não apresentou efeitos sobre os valores do ISQ. Foi observada correlação entre torque de inserção e baixos valores de ISQ, e, nos casos em que houve perda óssea perimplantar (defeitos verticais), os valores de ISQ também foram considerados baixos ${ }^{46}$. $\mathrm{Na}$ metodologia adotada, procurou-se padronizar o posicionamento da ponteira, a fim de criar um protocolo de aferição em que esta deveria estar perpendicular ao longo eixo do implante. Ainda, o valor final de ISQ foi a média dos resultados obtidos nas quatro direções (vestibular, lingual, mesial e distal), o que caracteriza a possibilidade de reprodutibilidade da pesquisa.

Estudos clínicos anunciam resultados promissores com implantes inseridos após extração dentária. No entanto, algumas vezes, ocorre um defeito ósseo inicial na região marginal desses implantes, que, de preferência, deveria cicatrizar para uma função adequada. Portanto, o monitoramento desses implantes torna-se essencial para obtenção de um prognóstico favorável.

Existe uma correlação entre a profundidade vertical do defeito ósseo e o valor da análise de frequência de ressonância. Esse método é sensível para detectar mudanças no nível do osso marginal e pode ser usado para monitorar a cicatrização de defeitos ósseos perimplantares ${ }^{47}$. Ou seja, quando ocorre fenestração do implante, sabe-se que há uma tendência de perda da estabilidade inicial. Por conseguinte, utiliza-se a análise de frequência por ressonância para avaliar essa possibilidade indesejada, no intuito de alterar o planejamento do carregamento do implante.

A fim de avaliar a interação entre osso e implante e correlacioná-la à aplicação de terapia complementar com três doses distintas de LLLT, realizou-se avaliação da densidade de imagem por meio de tomografia computadorizada de feixe cônico. A TC proporciona uma medida de densidade mineral óssea da mandíbula potencialmente útil como um método não invasivo para avaliar a qualidade óssea mandibular ${ }^{48}$. Entretanto, essa tecnologia não utiliza um sistema padrão para o dimensionamento dos níveis de cinza que representam os valores das reconstruções, o que torna difícil interpretar esses níveis para comparar os dados resultantes em equipamentos diferentes ${ }^{49}$.

Essa avaliação também foi realizada por meio de MEV e EDS, o qual analisa a superfície das amostras com o intuito de identificar, quantitativa e qualitativamente, padrões de formação óssea tecidual distinta.

Além das comparações mediante os exames de TCFC, AFR, MEV e EDS, utilizou-se a análise histológica realizada por coloração com HE, picrosirius-red e azul de toluidina, as quais têm fundamental relevância para verificar os efeitos do uso da LLLT. As avaliações do reparo ósseo e da resposta inflamatória são passíveis de serem evidenciadas pela técnica de coloração histológica HE. A análise da presença de fibras colágenas, bem como o padrão de distribuição desses tecidos nas regiões de periósteo, endósteo, medula e nas zonas de transição periósteo-medular e endósteo-medular, pode ser identificada pela técnica de coloração histológica picrosirius-red ${ }^{24}$. A coloração com azul de toluidina, por sua vez, foi realizada a fim de visualizar, pelo exame histomorfométrico, possíveis alterações na histologia óssea perimplantar, permitindo uma adequada distinção entre osso e implante, corando, em diferentes tons de azul, os componentes cortical e medular. Esse fato é importante por facilitar, por meio da visualização de uma imagem fotográfica, a mensuração da região a ser estudada, mesmo não informando, como em outras colorações, tipos celulares ou áreas em diferentes estágios de formação óssea. Em compensação, esse exame evidencia o volume ósseo para as mensurações da extensão linear de contato entre o tecido ósseo e a superfície do implante (ELCOI) e a área de tecido ósseo presente (AO), foco principal desse tipo de análise.

\section{Considerações finais}

Rotinas técnicas padronizadas para a realização de cada fase de um experimento qualificam uma linha de pesquisa de um grupo constituído com o objetivo de realizar uma sequência de análises que possam vir a responder a um conjunto de questões científicas de uma área delimitada do conhecimento na especialidade, com ênfase na laserterapia. Nesse campo do conhecimento em particular, enfrenta-se uma série de dificuldades, devido ao fato de as metodologias empregadas não se apoiarem nessa lógica de rotina e padronização no que se refere ao modelo animal experimental, assim como aos parâmetros de aplicação do laser, incluindo comprimento de onda e fluência ou dose. Apresenta-se, pois, um roteiro que pode servir de modelo para colegas pesquisadores. 


\section{Abstract}

Objectives: to describe surgical and laboratorial techniques used in an experimental rabbit model. The aim of the study was to obtain data using the following techniques: hormonal dosage, resonance frequency analysis (RFA), cone beam computed tomography (CBCT), scanning electron microscopy (SEM), energy dispersive spectrometry (EDS), peri-implant histological and histomorphometric analysis after low-level laser therapy (LLLT). Materials and method: a total of 40 New Zealand male rabbits were divided into five groups. Two groups designated control (Cl and CII) and three groups designated experimental (EI, EII, EIII). All groups underwent blood sampling for measurements of triiodothyronine (T3) and thyroxine (T4), calcium and albumin, with the CI group being considered absolute hematological control. For the other groups (CII, EI, EII and EIII) the extraction of the lower left incisor was performed followed by placement of an immediate implant with measurement of resonance frequency. The experimental groups were subjected to laser therapy with three different doses (EI $=70 \mathrm{~J} / \mathrm{cm}^{2}, E I I=35 \mathrm{~J} / \mathrm{cm}^{2}$, EIII $=140 \mathrm{~J} / \mathrm{cm}^{2}$ ). Groups CII, El, Ell and EIII were subjected to the measurement of resonance frequency after 45 days, killed and the jaw was dissected to be evaluated by CBCT, SEM and EDS. Then, the samples were included, sectioned and stained with HE staining, picrosirius-red and toluidine blue for histomorphometric analysis by linear extent of bone-implant contact (BIC) and bone area (BA) using light microscopy. Final considerations: a technical sequence that can provide a model for fellow researchers was presented.

Keywords: Dental implants. Low-level laser therapy. Methodology. Rabbits.

\section{Referências}

1. Brånemark P-I, Breine U, Adell R, Hansson BO, Lindström $\mathrm{J}$, Olsson A. Intra-osseous anchorage of dental protheses. Experimental studies. Scandinavian Journal of Plastic and Reconstructive Surgery 1969; 3(1):81-100.

2. Mangini RS, Schiochett C. Histórico dos implantes: do sonho à realidade. Rev Bras Odontol 1999; 56(5):245-51.

3. Albrektsson T, Johansson C, Lundgren A, Sul Y, Gottlow J. Experimental estudies on oxidized implant. A hisomorphometgrical and biomechanical analysis. Applied Osseoint Res 2000; 1(1):21-4.

4. Buser D, Weber HP, Bragger U, Balsinger C. Tissue integration of on stage ITI implants: 3 year results of longitudinal study with hollow-cylinder and hollow-screw implants. Int J Oral Maxillofac Impl 1991; 6(4):405-12.

5. Buser D, Dahlin C, Schenk RK. Regeneração óssea guiada na implantodontia. São Paulo: Quintessence Books; 1996.

6. Cochran DL, Buser D, Ten Bruggenkate CM, Weingart D, Tayor TM, Bernard JP, et al. The use of reduced healing times on ITI implants with sandblasted and acid-etched (SLA) surface: early results from clinical trials on ITI implants. Clin Oral Impl Res 2002; 13(2):144-53.

7. Thomas KA, Cook SD. An evaluation of variables influencing implant fixation by direct bone apposition. J Biom Mater Res 1985; 19(8):875-901.
8. Sul YT, Johansson CB, Jeong Y, Roser K, Wennerberg A, Albrektsson T. Oxidized implants and their influence on the bone response. J Mater Sci Mater Med 2001; 12(10):102531.

9. Ostman PO, Hupalo M, Del Castillo R, Emery RW, Cocchetto R, Vincenzi G, et al. Immediate provisionalization of NanoTite implants in support of single-tooth and unilateral restorations: one-year interim report of a prospective, multicenter study. Clin Implant Dent Relat Res 2010 May; 12 Suppl 1:e47-55.

10. Lazzara RJ. NanoTite ${ }^{\mathrm{TM}}$ implants: the next generation of dental implants. Clinical Perspectives [artigo online] 2007; 6(1). Disponível em URL: http://br.biomet3i.com/Pdf/Art995B_Nano_CP.pdf.

11. Sennerby L. The implant stability quotient whitebook: the relationship between reliable diagnostics and safe, successful dental implant procedures [livro on line]. Disponível em URL: http://www.osstell.com/filearchive/4/4009/25045-01\%20EN\%20ISQ\%20Whitebook_lr.pdf.

12. Freddo AL, Rodrigo SM, Massotti FP, Etges A, Oliveira MG. Effect of low-level therapy after implantation of poly-L-lactic/polyglycolic acid in the femurs of rats. Laseres Med Sci 2009; 24(5):721-8.

13. Ross G, Ross A. Low level laser therapy: an untapped resource in the dental industry. Oral Health 2009; 99(12):27-8.

14. Almeida-Lopes L. Laserterapia na Odontologia. Bauru: Clínica Odontológica Integrada; 2003.

15. Rochkind S, Rousso M, Nissan M, Villarreal M, Barr-Nea L, Rees DG. Systemic effects of low-power laser irradiation on the peripheral and central nervous system, cutaneous wounds, and burns. Lasers Surg Med 1989; 9(2):174-82.

16. Pérez de Vargas I, et al. Acción del laser IR sobre la glândula tiroides . Histologia Medica 1987; 3(1):117-26.

17. Parrado C, Peláez A, Vidal L, Pérez de Vargas I. Quantitative study of the morphological changes in thyroid gland following IR laser irradiation. Lasers in Medical Science 1990; 5(1):77-80.

18. Azevedo LH, Aranha AC, Stolf SF, Eduardo CP, Vieira MM. Evaluation of low intensity laser effects on the thyroid gland of male mice. Photomed Laser Surg 2005; 23(6):567-70.

19. Lopes CB, Pinheiro AL, Sathaiah S, Da Silva NS, Salgado MA. Infrared laser photobiomodulation (lambda $830 \mathrm{~nm}$ ) on bone tissue around dental implants: a Raman spectroscopy and scanning electronic microscopy study in rabbits. Photomed Laser Surg 2007; 25(2):96-101.

20. Pinheiro AL, Gerbi ME. Photoengineering of bone repair processes. Photomed Laser Surg 2006; 24(2):169-78.

21. Khadra M, Lyngstadaas SP, Haanaes HR, Mustafa K. Effect of laser therapy on attachment, proliferation and differentiation on human osteoblast-like cells cultured on titanium implant material. Biomaterials 2005; 26(17):3503-9.

22. Pinheiro ALB, Limeira Júnior FA, Gerbi ME, Pedreira Ramalho LM, Marzola C, Carneiro Ponzi EA, et al. Effect of $830 \mathrm{~nm}$ laser light on repair of bone defects grafted with organic bovine bone and decalcified cortical osseous membrane. J Clin Laser Med Surg 2003; 21(6):383-8.

23. Gerbi ME, Pinheiro AL, Marzola C, Limeira Júnior FA, Ramalho LM, Ponzi EA, et al. Assessment of bone repair associated with the use of organic bovine bone and membrane irradiated at 830nm. Photomed Laser Surg 2005; 23(4):382-8. 
24. Guimarães KB. Fotoengenharia do processo de reparo ósseo induzido pela laserterapia de baixa potência (GaAlAs): estudo em fêmures de ratos [Dissertação de Mestrado]. Porto Alegre: Pontifícia Universidade Católica do Rio Grande do Sul; 2006.

25. Scarfe WC, Farman A, Sukovic P. Clinical applications of cone-beam computed tomography in dental practice. J Can Dent Assoc 2006; 72(1):75-80.

26. Xaves ACC, Sena LEC, Araújo LF, Nascimento Neto JBS. Aplicações da tomografia computadorizada de feixe cônico na Odontologia. Int J of Dentistry 2005; 4(3):80-124.

27. Parks ET. Computed tomography applications for dentistry. Dental Clin North Am 2000; 44(2):371-94.

28. Dedavid BA. Microscopia eletrônica de varredura: aplicações e preparação de amostras: materiais poliméricos, metálicos e semicondutores. Porto Alegre: EDIPUCRS; 2007.

29. Garg A. Osstell ${ }^{\mathrm{TM}}$ mentor: measuring dental implant stability at placement, before loading, and after loading. Dental Implantology Update 2007; 18(7).

30. Campanha BP, Gallina C, Geremia T, Loro RC, Valiati R, Hübler R, et al. Low-level laser therapy for implants without initial stability. Photomed Laser Surg 2010; 28(3):365-9.

31. Timlin JA, Carden A, Morris MD. Chemical microstructure of cortical bone probed by Raman transects. Appl Spectr 1999; 53(5):1429-35.

32. Pereira CL, Sallum EA, Nociti FH Jr, Moreira RW. The effect of low-intensity laser therapy on bone healing around titanium implants: a histometric study in rabbits. Int $\mathrm{J}$ Oral Maxillofac Implants 2009; 24(1):47-51.

33. Khadra M, Ronold HJ, Lyngstadaas SP, Ellingsen JE, Haanaes HR. Low-level laser therapy stimulates boneimplant interaction: an experimental study in rabbits. Clin Oral Implants Res 2004; 15(3):325-32.

34. De Jong WC, Korfage JA, Langenbach GE. Variations in habitual bone strains in vivo: long bone versus mandible. $\mathrm{J}$ Struct Biol 2010; 172(3):311-8.

35. Gilsanz V, Roe TF, Gibbens DT, Schulz EE, Carlson ME, Gonzalez O, et al. Effect of sex steroids on peak bone density of growin rabbits. Am J Physiol 1988; 255:416-21.

36. Turner AS. Animal models of osteoporosis: necessity and limitations. European Cells and Materials 2001; 1(1):66-81.

37. Brugnera A Jr, Santos AECG, Bologna ED, Landalardo TCCGP. Atlas de laserterapia aplicada à clínica odontológica. São Paulo: Santos; 2003.

38. Miloro M, Miller JJ, Stoner JA. Low-level laser effect on mandibular distraction osteogenesis. J Oral Maxillofac Surg 2007; 65(2):168-76.

39. Blaya DS, Guimarães MB, Pozza DH, Weber JBB, Oliveira MG. Histologic study of the effect of laser therapy on bone repair. J Contemp Dent Pract 2008; 9(6):41-8.

40. Dörtbudak O, Haas R, Mailath-Pokorny G. Effect of lowpower laser irradiation on bony implant sites. Clin Oral Implants Res 2002; 13(3):288-92.

41. Lopes CB, Pinheiro AL, Sathaiah S, Duarte J, Cristinamartins M. Infrared laser light reduces loading time of dental implants: a Raman spectroscopic study. Photomed Laser Surg 2005; 23(1):27-31.
42. Smith-Agreda V, et al. Aportaciones al estudio de las interacciones morfoquímicas de las células adenohipofisarias tras la estimulación com laser $\mathrm{He} / \mathrm{Ne} 632,8 \mathrm{~nm}$ de baja potencia. Investigacion y Clinica Laser 1985; 2(1):51-62.

43. Parrado C, et al . Estudio morfometrico de la glandula tiroides sometida a irradiacion laser IR II. Densidad de volumen epitelial e inverso del indice de activacion. Histologia Medica $1988 ; 4(2): 93-8$.

44. Meredith N. Assessment of correlation between computerized tomography values of the bone, and maximum torque and resonance frequency values at dental implant placement. Int J Prosthodont 1998; 11(5):491-501.

45. Balleri P, Cozzolino A, Ghelli L, Momicchioli G, Varriale A. Stability measurements of osseointegrated implants using Osstell in partially edentulous jaws after 1 year of loading: a pilot study. Clin Implant Dent Relat Res 2002; 4(3):128-32.

46. Ohta K, Takechi M, Minami M, Shigeishi H, Hiraoka M, Nishimura M, et al. Influence of factors related to implant stability detected by wireless resonance frequency analysis device. J Oral Rehabil 2010; 37(2):131-7.

47. Turkyilmaz I, Sennerby L, Yilmaz B, Bilecenoglu B, Ozbek En. Influence of defect depth on resonance frequency analysis and insertion torque values for implants placed in fresh extraction sockets: a human cadaver study. Clin Implant Dent Relat Res 2009; 11(1):52-8.

48. Lindh C, Nilsson M, Klinge B, Petersson A. Quantitative computed tomography of trabecular bone in the mandible. Dentomaxillofac Radiol 1996; 25(3):146-50.

49. Mah P, Reeves TE, Mcdavid DW. Deriving Hounsfilds units using grey levels in cone beam computed tomography. Dentomaxillofac Radiol 2010; 39(6):323-35.

Endereço para correspondência:

Luciano Mayer

Rua Felipe Neri 296/403.

Bairro Auxiliadora - Porto Alegre, RS, Brasil.

Fone: + 55 (51) 3388-8452

E-mail: contato@clinicamayer.com.br

Recebido: 14/03/2013. Aceito: 01/10/2013 